\title{
Electric fence planning for dockless bike-sharing services
}

Yongping Zhang ${ }^{1,2}$, Diao $\mathrm{Lin}^{3}$, Zhifu $\mathrm{Mi}^{4, *}$

1. Zhou Enlai School of Government, Nankai University, 300350, Tianjin, China

2. The Bartlett Centre for Advanced Spatial Analysis, University College London, 90 Tottenham Court Road, W1T 4TJ, London, UK

3. Chair of Cartography, Technical University of Munich, Arcisstraße 21, 80333 Munich, Germany

4. The Bartlett School of Construction and Project Management, University College London, WC1E 7HB, London, UK

Abstract: A new generation of bike-sharing services is emerging in China. With this service, bikes can be unlocked and paid by using a smartphone and then picked up and left anywhere at users' convenience. The unprecedented development of dockless bike-sharing services results in considerable socioeconomic and environmental benefits but also creates new urban issues. One of the most severe issues is users' inappropriate parking behaviour. To solve this problem, electric fence (or geo-fence) policy and technology have been introduced in China to guide users to park bikes in designated zones. In this paper, we first propose a methodological framework to support electric fence planning for dockless bike-sharing services. We then apply our framework in a case study of Shanghai using a big dataset of bike trips. Results show that when the number of planned electric fences is 7,500 , our electric fence plan can cover $91.8 \%$ of total parking demand. In addition, our plan can ensure that at least $95.8 \%$ of all bikes can be docked at one of planned electric fences and can help efficiently and accurately determine suitable locations for setting up planned electric fences.

\footnotetext{
* Corresponding author address: The Bartlett School of Construction and Project Management, University College London, WC1E 7HB, London, UK

Email: zhangyongping2112@gmail.com (Y.Zhang), diao.lin@tum.de (D. Lin), z.mi@ucl.ac.uk (Z.Mi)
} 
Keywords: Dockless bike-sharing, electric fences, location allocation model, big data, Shanghai

\section{Highlights:}

1) We discuss electric fence (geo-fence) policy and technology used to regulate inappropriate parking behaviour of dockless bike users.

2) We propose a methodological framework to support electric fence planning for dockless bike-sharing services.

3) We apply our framework in a case study of Shanghai and present the results in six scenarios.

4) We adopt a big data approach to support our analysis. The dataset contains 777,896 trips with 298,998 bikes.

\section{Introduction}

As a form of sustainable transport, bike-sharing is becoming increasingly popular in cities around the world (Kabak et al., 2018; O'Brien et al., 2014). This popularity can be explained by the association of bike-sharing with various socioeconomic and environmental benefits, such as a decrease in $\mathrm{CO}_{2}$ emissions, a reduction in diseases, and a decline in traffic congestion and noise pollution through the provision of alternatives to auto commuting and an increase in public transit use (Caulfield et al., 2017; Ji et al., 2014; Martens, 2007). We are now facing a new generation of bike-sharing, referred as internet-based dockless bike-sharing, which is currently emerging in China and expanding worldwide (Zhang and Mi, 2018). Prior to such dockless services, bikes needed to be docked at stations. However, in this emerging service, bikes can be unlocked and paid by using a smartphone and then picked up and left anywhere at users' convenience. Dockless bike-sharing is developing at an unprecedented speed. As of July 2017, approximately 16 million dockless bikes are available in China and 50 million orders per day are generated by 106 million users. Taking ofo, the first 
and a leading dockless bike-sharing company, as an example, it has entered the markets of nine countries and 170 cities, such as London (the UK) and Singapore (The Centre for Sharing Economy, 2017).

The rapid development greatly magnifies the various benefits of bike-sharing to support the achievement of sustainable cities, but also generates new urban issues. Among these issues, the most serious may be inappropriate parking behaviour. With the convenience of 'docklessness' or 'free to leave' policies, a non-negligible number of users parks bikes at places that are unsuitable as parking spaces (e.g., on a pedestrian street, closely adjacent to a metro entrance, or inside a gated community), thereby resulting in negative impacts (e.g., violating the pedestrian right-of-way, impeding the movement of metro users, or making bikes not easily available to subsequent users) (Chang et al., 2018; Shi et al., 2018; Yu and Shang, 2018).

An electric fence (or a geo-fence) is traditionally defined as a barrier protecting economically and ecologically sensitive areas. Most electric fences are used today for agricultural fencing and other forms of animal control (Reidy et al., 2008). Now, the Chinese government and main bike-sharing service providers regard electric fence policy and technology as the first choice for regulating inappropriate parking behaviour by preventing users from parking bikes in prohibited regions and guiding users to park bikes in designated zones. An electric fence for dockless bike-sharing is a predetermined 'virtual fence' without a physical installation. The system of electric fences works using Global Positioning Systems (GPS), Radio Frequency Identification Device (RFID), or Bluetooth signals to determine the proximity between bikes and designated zones. Users who park bikes outside the allowed areas cannot lock them and will continue to be charged. Bike riders will also be guided by their app or navigation voices to proper parking locations. The technology allows operators to specify where a bike can be safely parked, or create an exclusion zone that prevents the bike from being manually locked. Electric fence policy and technology have been recommended in several important 
governmental documents, such as 'the National Guidance to Encourage and Regulate the Development of the Internet-based Dockless Bike-sharing Service', which has been promulgated by the Chinese National Ministry of Transport in August 2017. Such technology and policy have also been tested as pilot projects in several cities in China (e.g., Beijing, Chengdu, and Hangzhou) since early 2017. Besides China, other countries have adopted the similar strategy to regulate the users' inappropriate parking behaviour. For example, Transport for London (2017) requires that all dockless bike-sharing operators must make that an obstruction does not arise because of the deposit of bikes, and that bikes are not deposited in predesignated no-go areas such as around fire escapes through the implementation of geographic controls or geo-fencing.

As a first effort to discuss the electric fence policy and technology, this paper mainly focuses on developing a methodological framework to support electric fence planning for dockless bike-sharing services, and then applying it in a case study of Shanghai using a big dataset of bike trips provided by Mobike, one of the largest dockless bike-sharing service providers in the world. The key method used to support electric fence planning is the location-allocation model, which has also been widely applied in the planning of various urban facilities (including bike stations) (Park and Sohn, 2017; Rahman and Smith, 2000). Basically, electric fence planning can be regarded as an optimisation problem which can be solved by the location-allocation model: based on a certain number of electric fences and the distribution of parking demand, the goal of the location-allocation model is to locate the electric fences in the most efficient way to meet the parking demand (Park and Sohn, 2017). The main data used in this paper is a user-generated bike trip data, which can be regarded as a type of urban big data, and can make it easier to accurately delineate the users' parking demand.

The main contributions of this study are listed as follows:

1) We discuss how to support location planning of electric fences, which are used to regulate inappropriate parking behaviour among dockless bike users. 
2) We propose a methodological framework to support electric fence planning for dockless bike-sharing services. The framework can be applied in any urban context, assuming relevant data are available.

3) We apply our framework in a case study of Shanghai and present the electric fence plans in six scenarios. Mobike is the one of the largest dockless bike-sharing companies in the world, while Shanghai is the one of the largest bike-sharing markets in the world. The choice of case study makes the analytical results more representative.

4) A big data approach is adopted in this study. Compared with the small data approach, the big data approach utilises the data which contains a much larger sample size and are collected automatically (Zhang and $\mathrm{Mi}, 2018$ ). As a result, it can represent the parking demand more accurately and in an economically saving and efficient way. The outcomes of the electric fence plans are also more likely to be representative.

The paper is organised as follows. Following this introduction, we present a relevant review in Section 2, followed by a description of our methods in Section 3. Our case study using a bike trip dataset from Shanghai, China is described in Section 4, and we end the paper with our conclusions and a discussion in Section 5.

\section{Relevant review}

In this section, we present a review about relevant literature. Section 2.1 reviews the existing studies related to dock-based bike-sharing services. These studies are grouped into three domains: analysis of bike-sharing's characteristics, bike-sharing rebalancing analysis, and bike-sharing's facility location planning. Section 2.2 gives a review about the existing studies related to dockless bike-sharing services.

\subsection{Dock-based bike-sharing service analysis}

\subsubsection{Analysis of bike-sharing's characteristics}


The studies in the first domain include those that characterise bike sharing through various analyses. Wood et al. (2011) visualised the dynamics of London's bike-sharing scheme using flow maps. Zaltz Austwick et al. (2013) employed visualisation, descriptive statistics and spatial and network analysis tools to explore usage in five cities around the world. Beecham et al. (2014) proposed a new technique for classifying commuting behaviours, and it involved various spatial analysis algorithms and visual analytics techniques. In addition, Caulfield et al. (2017) examined usage patterns of a bike-sharing programme in Cork, a medium-sized city in Ireland. This research provides insights into the dynamics of a relatively small bike-sharing scheme and assesses how bike sharing has offered citizens a new transportation alternative. Researchers may have a particular interest in understanding the factors that affect bike sharing (such as the built environment, weather, and socioeconomic demographics) (Bachand-Marleau et al., 2012; El-Assi et al., 2017; Faghih-Imani et al., 2014). Most previous studies have focused on the analysis of an individual city, such as London (the United Kingdom) (Ogilvie and Goodman, 2012; Pfrommer et al., 2014; Wood et al., 2011), Washington, D.C. and Seattle (the United States) (Buck et al., 2013; Buehler, 2012; Rixey, 2013), Toronto and Montreal (Canada) (Fuller et al., 2011; Habib et al., 2014), and Hangzhou and Zhongshan (China) (Chen et al., 2017; Shaheen et al., 2011; Zhang et al., 2017), Singapore (Shen et al., 2018), Hanover (Germany) (Campbell et al., 2008). However, studies have also performed comparative analyses of the bike-sharing systems in different cities. These comparisons are based on numerous aspects, such as the number of subscribers/stations/bikes, modal share changes, connectivity, and flows ( $O^{\prime}$ Brien et al., 2014; Zaltz Austwick et al., 2013; Zhang et al., 2015).

\subsubsection{Analysis of bike-sharing rebalancing}

The second domain of dock-based bike-sharing service analysis includes mathematical models that focus on rebalancing. How to balance the bike-sharing stations to prevent them from becoming too full or too empty is an important issue. There are some studies focusing 
on the debate of the rebalancing issue. Taking London's Barclays Cycle Hire programme as a study case, Pfrommer et al. (2014) considered the efficient operation of shared mobility systems via the combination of intelligent routing decisions for staff-based vehicle redistribution and real-time price incentives for customers. Forma et al. (2015) proposed a three-step mathematical programming-based heuristic method for the static repositioning problem. Erdoğan et al. (2015) proposed the Static Bicycle Rebalancing Problem, seeking not only to decide the amount of bicycles to be assigned to each station but also to minimise the cost of stations to be stopped by a few vehicles. Pal and Zhang (2017) presented a novel mixed integer linear programme for solving real-life large-scale static rebalancing problems.

\subsubsection{Bike-sharing's facility location planning}

Facility location is one of the most important factors in strategic decision making by the public sector (Frade and Ribeiro, 2015). The studies in the third domain focus on the development of various methods to support bike-sharing's facility location planning, particularly optimising the locations of bike stations. Supply-based bike facility planning has relied on quantitative models, such as a bicycle level of service (Landis et al., 1997) and a bicycle compatibility index (Harkey et al., 1998) to assess roadway conditions for bicyclists, or the combination of multi-criteria decision-making (MCDM) methods and geographic information system (GIS) to evaluate site suitability for bike-share stations (Kabak et al., 2018). Additional studies have attempted to develop bicycle demand models to plan bike facilities because the success of bike sharing as a public transport mode depends largely on how user demand is met (Frade and Ribeiro, 2015; García-Palomares et al., 2012; Rybarczyk and $\mathrm{Wu}, 2010)$.

Among the existing approaches to supporting bike station planning, location-allocation model has been proved to be of great use for locating bike stations with relation to the distribution of potential demand (García-Palomares et al., 2012). Since the first studies of 
location-allocation model were carried out (e.g., Cooper, 1963), location-allocation model has been widely applied in the planning of various urban facilities (Rahman and Smith, 2000). With respect to public services, the most frequent applications are for health care facilities (Verter and Lapierre, 2002), fire stations (Liu et al., 2006), schools (Teixeira et al., 2007), and waste disposals (List and Mirchandani, 1991), etc. There are also some studies that use location-allocation model to optimise the locations of bike stations. García-Palomares et al. (2012) proposed a GIS-based method to calculate the spatial distribution of the potential demand for trips, locate stations using location-allocation models, determine station capacity, and define the characteristics of the demand for stations. Frade and Ribeiro (2015) adopted an optimisation method to design a bike sharing system that maximises the covered demand and considers the available budget as a constraint. Based on taxi trajectory data, Park and Sohn (2017) proposed a framework for most efficiently locating bicycle-sharing stations to replace short automobile trips.

Although specific considerations for electric fence planning are required because the characteristic of 'docklessness' creates a considerable difference between dockless bike-sharing services and dock-based services, the existing studies on dock-based bike-sharing's facility location planning have provided a good reference to the study in this paper. From the existing studies, it is easy to know there are some approaches which have the potential to be used here, such as a bicycle level of service (BLOS) (Landis et al., 1997), a bicycle compatibility index (Harkey et al., 1998), and the location-allocation model (García-Palomares et al., 2012). However, it should be noted that different methods require different datasets. Taking BLOS as an example, this measure is a function of per-lane motor vehicle traffic volume, speed of motor vehicles, traffic mix, potential cross-street traffic generation, pavement surface condition, and pavement width for bicycling (Landis et al., 1997). These data are currently difficult to be obtained in Shanghai. The main data we obtained is a user-generated bike trip data, which make it easier to accurately delineate the users' parking demand. Considering the data availability, the location-allocation model, as a 
demand-based method, is chosen as our main method to support electric fence planning for dockless bike-sharing services.

\subsection{Dockless bike-sharing service analysis}

When it comes to the phenomenon of dockless bike-sharing services, because it is just emerging in recent years and relevant trip data are not easily obtainable for various reasons, such as privacy issues and business secrets, we could find a limited number of studies about dockless bike-sharing services. Bao et al. (2017) proposed a data-driven approach to developing bike lane construction plans based on bike trip data. Using big data techniques, Zhang and Mi (2018) estimated the impacts of bike sharing on energy use and carbon dioxide $\left(\mathrm{CO}_{2}\right)$ and nitrogen oxide (NOX) emissions in Shanghai from a spatiotemporal perspective. They found that, in 2016, bike sharing in Shanghai saved 8358 tonnes of petrol and decreased $\mathrm{CO}_{2}$ and NOX emissions by 25,240 and 64 tonnes, respectively. Tian et al. (2018) presented a hybrid fuzzy multi-criteria decision-making approach to increasing the knowledge on the smart bike-sharing services. Shen et al. (2018) analysed the usage patterns of dockless bike-sharing in Singapore using the GPS data of all dockless bikes from one of the largest bike sharing operators in Singapore. Ai et al. (2018) developed a deep learning approach on short-term spatiotemporal distribution forecasting of dockless bike-sharing services. Pan et al. (2018) focused on how to rebalance the distribution of dockless bikes in cities by using an algorithm called Loss-Reduced Reinforcement Pricing. Liu et al. (2018) tried to solve the problem of inferring dockless bike distribution in new cities, by learning insights on bike distribution from cities populated with dockless bikes. Zhou and Ni (2018) explored factors affecting the dockless bike-sharing on modal shift in metro commuting. They found time of walking or bus riding is the most critical factor. Besides, good riding skill, non-motorised vehicle owner, and metro locations outside the city centre pose significantly positive effects on modal shift. Based upon a series of stakeholder interviews and media analysis, Spinney and Lin (2018) concluded that dockless bike-sharing represents a retrenchment and extension of existing exploitative capitalist relations. Ma et al. (2018) 
examined how commercial, political and social actors interact in addressing the emerging public problems in the dockless bike-sharing from a collaborative governance perspective. Yu and Shang (2018) analysed the advantages of bike sharing from the perspectives of policy support, low carbon, easing traffic congestion and enormous potential customers, and its disadvantages from the points of inappropriate parking, malicious sabotaging, excessive input of bikes and trust crisis. Xin et al. (2018) adopted the structural equation model to measure what factors influence people's willingness to use the system and how the indicators inside the system interact with each other. Chen et al. (2018) took station-based bike-sharing system with docks and dockless free-floating bike-sharing system as two targets to dig out the relationship between users and use frequency of the services for each scheme, and how the relationship varies from one programme to another.

Although there are some existing studies discussing dockless bike-sharing, some of them also mentioned about the electric fence policy and technology (Shi et al., 2018; van Waes et al., 2018), to the best of our knowledge, there is no existing study systematically and quantitatively discussing and supporting the planning of electric fences for dockless bike-sharing. This paper aims to fill this gap by developing a methodological framework using a big dataset of bike trips.

\section{Methodological framework}

Our methodological framework consists of six steps. Step 1 to 3 prepare three main data sources: road network, parking demand, and location candidates for electric fences; In Step 4, we use the location-allocation model to plan electric fences; Step 5 determines capacities of planned electric fences; and Step 6 recommends accurate locations for planned electric fences. We explain our framework step by step in the following text. 


\section{Step 1: Construct road network}

In this study, all bikeable roads in Shanghai are extracted using OSMnx, which is an analytical package for downloading administrative boundary shapes and street networks from OpenStreetMap (Boeing, 2017). After obtaining bikeable roads, we construct the bike road network using ArcGIS, a widely used GIS software.

\section{Step 2: Extract parking demand}

Each trip in our dataset contains its origin and destination (OD). Therefore, parking demand can be extracted directly from users' real parking behaviour based on the bike trip dataset. We first divide the study area into uniform urban cells (or urban grids), then we count the number of ODs in each cell, which is used to represent the cell's parking demand (Park and Sohn, 2017).

\section{Step 3: Select location candidates for electric fences}

High parking demand in an urban cell usually means that users are more willing to park bikes there, and this cell may also have sufficient space for bike parking. Therefore, selecting urban cells as location candidates for electric fences can be based on the parking demand: an urban cell with a number of ODs higher than a predetermined value is selected as a location candidate.

\section{Step 4: Select locations for electric fences}

Based on a certain number of electric fences and the distribution of parking demand, the goal of the location-allocation model is to locate the electric fences in the most efficient way to meet the parking demand. Several methods have been commonly used to solve the location-allocation model, such as minimise impedance, maximise coverage, and minimise facilities (Park and Sohn, 2017). In this study, we solve the location-allocation model by using the maximise coverage method. To explain the location-allocation model more clearly, we 
first introduce the following notations:

i index of demand locations (i.e., urban cells), $i=1,2, \ldots, n$

j index of location candidates for electric fences, $j=1,2, \ldots, m$

$\mathrm{d}_{\mathrm{ij}}$ the network distance between $\mathrm{i}$ and $\mathrm{j}$

D the impedance cut-off considered for the network distance

$\mathrm{N}_{\mathrm{i}}$ a set of location candidate $\mathrm{j}$ within a distance $\mathrm{D}$ from demand location $\mathrm{i}$

$\mathrm{u}_{\mathrm{i}}$ the number of ODs in the $\mathrm{i}$ th demand location (amount of demand)

$\mathrm{p}$ the number of locations to be selected as electric fences (predetermined)

$x_{i} 1$, if the demand location $i$ is satisfied; 0 , otherwise

$y_{j} 1$, if the location candidate $j$ is selected as an electric fence; 0 , otherwise

The objective of the maximise coverage method to solve the location-allocation model is to maximise the demand covered by $\mathrm{p}$ electric fences. The mathematical model is formulated as followed:

Maximise: $\sum_{\mathrm{i}=1}^{\mathrm{n}} \mathrm{u}_{\mathrm{i}} \mathrm{x}_{\mathrm{i}} \quad(1)$

such that

$\sum_{\mathrm{j} \in \mathrm{N}_{\mathrm{i}}} \mathrm{y}_{\mathrm{j}} \geq \mathrm{x}_{\mathrm{i}}$

$\sum_{\mathrm{j}=1}^{\mathrm{m}} \mathrm{y}_{\mathrm{j}}=\mathrm{p}(3)$

$\mathrm{x}_{\mathrm{i}}, \mathrm{y}_{\mathrm{j}}=(0,1)(4)$

$\mathrm{N}_{\mathrm{i}}=\left\{\mathrm{j} \mid \mathrm{d}_{\mathrm{ij}} \leq \mathrm{D}\right\}(5)$

To achieve its objective, the maximise coverage method seeks to maximise the demand coverage of electric fences, as expressed in formula (1). At least one electric fence must be within $\mathrm{D}$ from $\mathrm{i}$ to meet the $\mathrm{i}$ 's parking demand, as shown in constraint (2). 


\section{Step 5: Determine capacities of electric fences}

Considering that the results of the location-allocation model provide the amount of potential parking demand allocated to each electric fence, converting the amount of each electric fence's demand into the number of bikes that can be docked in this electric fence is simple: the total number of bikes simply can be distributed among the different electric fences in proportion to the demand allocated to each electric fence (García-Palomares et al., 2012). For example, the total number of bikes are 1200 , the total parking demand is 10,000 ODs, and the demand allocated to an electric fence is $100 \mathrm{ODs}$, then the capacity of this electric fence is $1200 *(100 / 10000)=12$ bikes. However, in reality, the capacities are more likely to be designed according to several fixed levels (e.g., 10 or 20 bikes per electric fence), rather than various non-fixed values (e.g., 7 or 13 bikes per electric fence). Therefore, after determining the number of bikes based on the covered parking demand, we further determine the capacities of electric fences according to several fixed capacity levels, which are designed by relevant stakeholders. For the above example, the capacity of this electric fence may be determined as 10 , instead of 12 bikes.

\section{Step 6: Recommend accurate places for electric fences}

After selecting the locations for electric fences, the locations (i.e., uniform cells) where electric fences should be located are known. However, the most accurate site at a selected location for setting up an electric fence must be clarified based on the size of the electric fence (e.g., $2 * 15$ metres), which is much smaller than an urban cell (e.g., $50 * 50$ metres).

Here, we propose a method of determining accurate sites that present a high density of parking demand in a selected location. A high density of parking demand means there exists a high number of ODs in a relatively small area. This site then is recommended as an accurate and suitable location for setting up an electric fence. The method is described as follows.

1) Clustering ODs in the selected location using DB-SCAN (density-based spatial clustering of applications with noise) (Ester et al., 1996). For a set of demand points in 
space, DB-SCAN can group together points that are densely packed together (points with many nearby neighbours) as a cluster and mark points that lie alone in low-density regions as outliers (whose nearest neighbours are too far away). DB-SCAN requires only two parameters: Eps, the search radius (e.g., 3 metres) of neighbourhood, and MinPts, the minimum number of ODs in an Eps-neighbourhood (e.g., 2 ODs) (Zhang and Liu, 2018).

2) Finding the cluster that contains the largest number of ODs among all clusters identified for each selected location.

3) Calculating the mean centre of the cluster with the largest number of ODs. The mean centre represents the geographic centre (or the centre of concentration) for a set of ODs.

4) Delineating the minimum bounding rectangle of the cluster with the largest number of ODs. The minimum bounding rectangle is the rectangle of the smallest area enclosing a set of ODs, and it is regarded as an approximation of the shape of an electric fence.

The mean centre and minimum bounding rectangle of the cluster with the largest number of ODs in a selected location can help us efficiently and accurately determine suitable locations for setting up an electric fence. Figure 1 illustrates an example of the whole process of electric fence planning. In this example, the study area consists of $5 * 5$ locations, and the target is to plan one electric fence. 


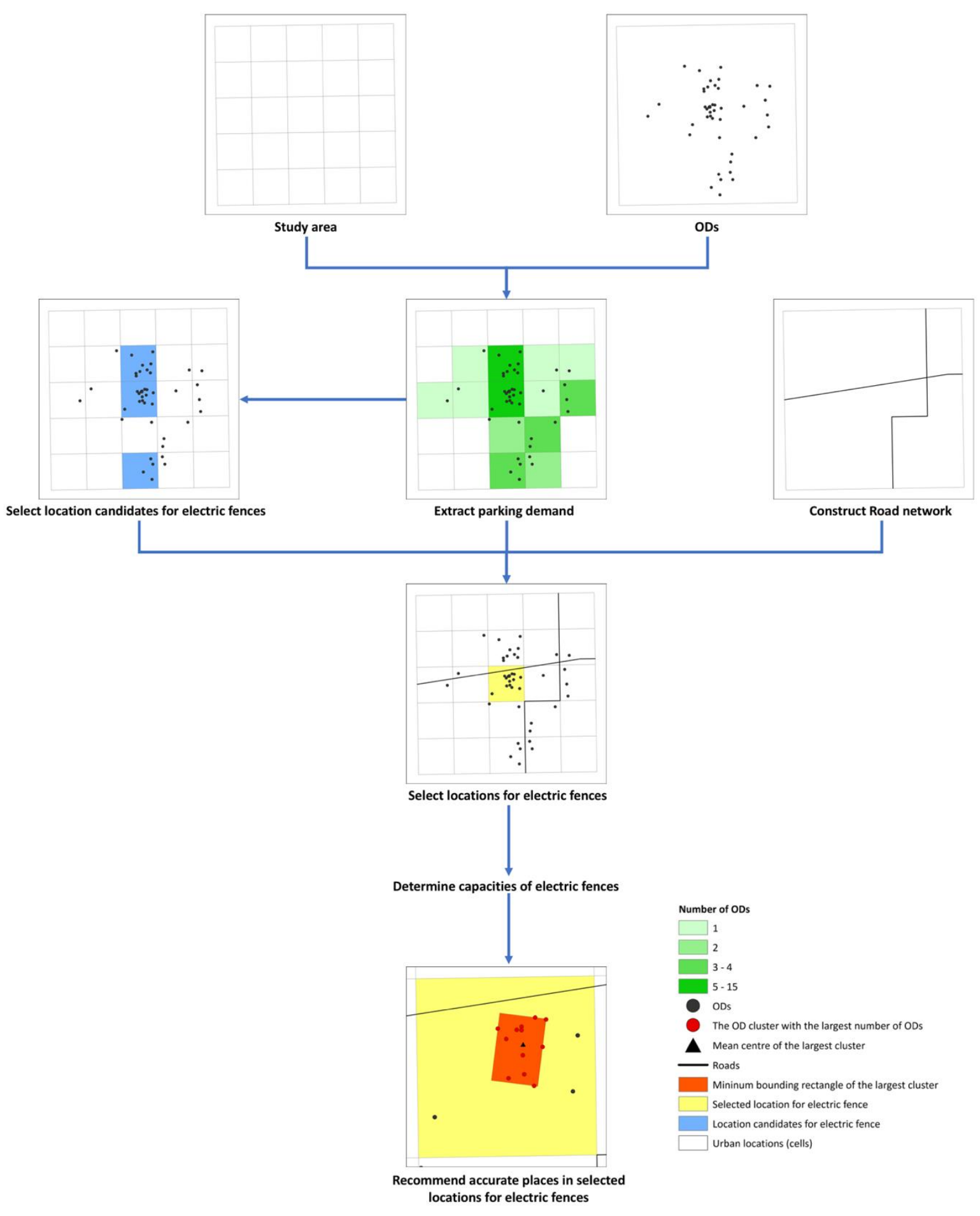

Figure 1. Example of the electric fence planning process.

\section{Case Study}

Shanghai is chosen as our study area (Figure 2A). This section presents the analytical results 
in Shanghai according to the steps described in our methodological framework.

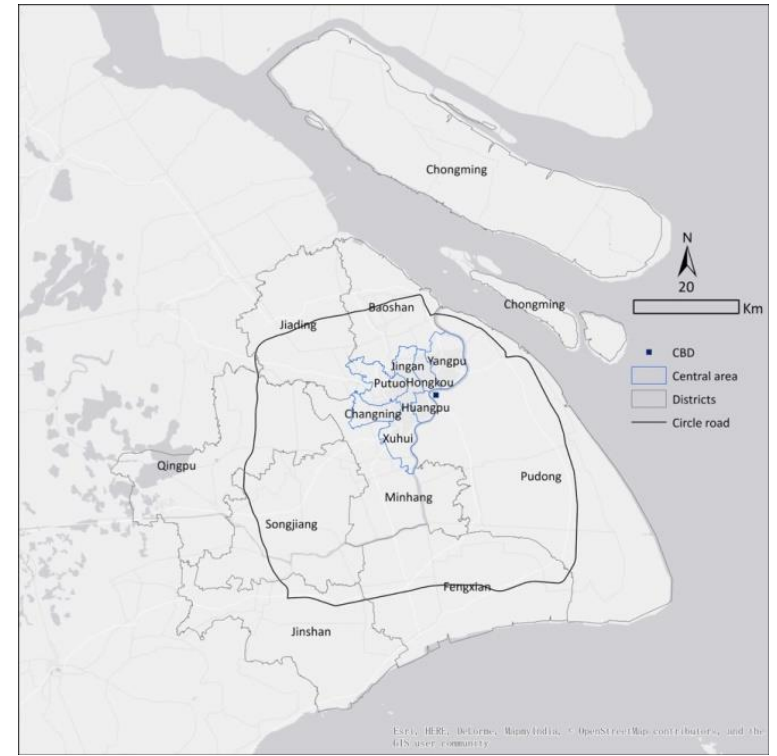

A

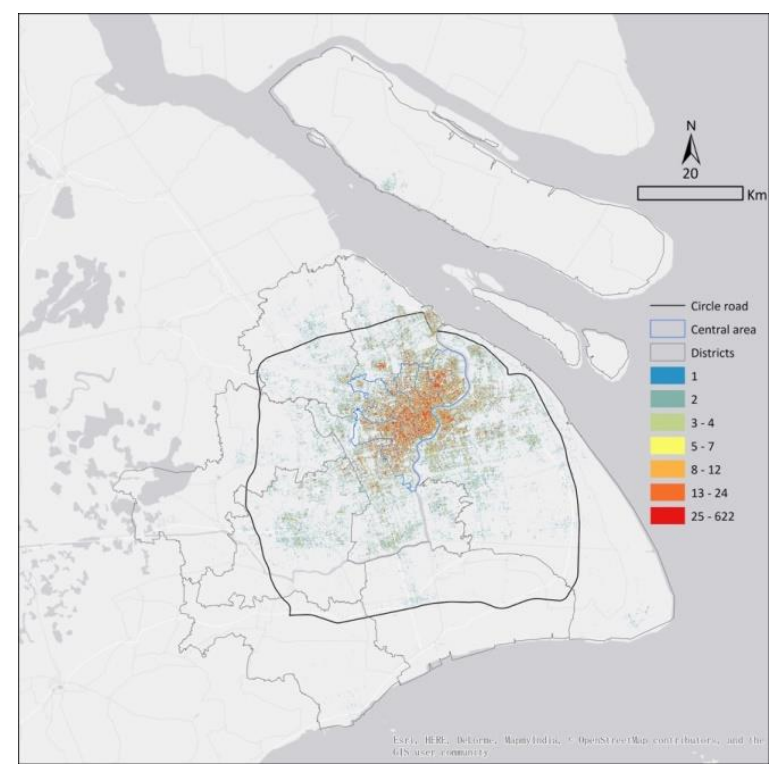

C

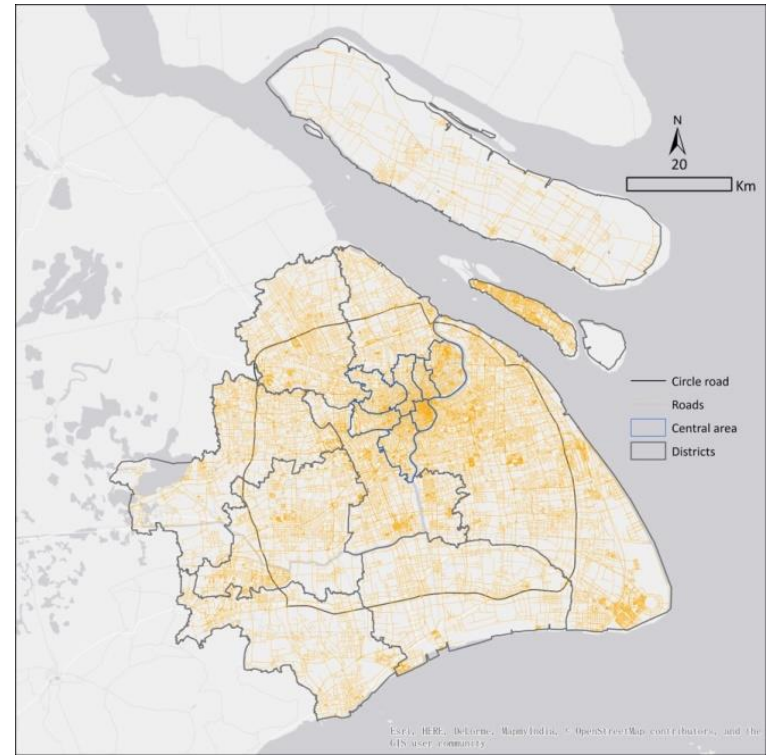

B

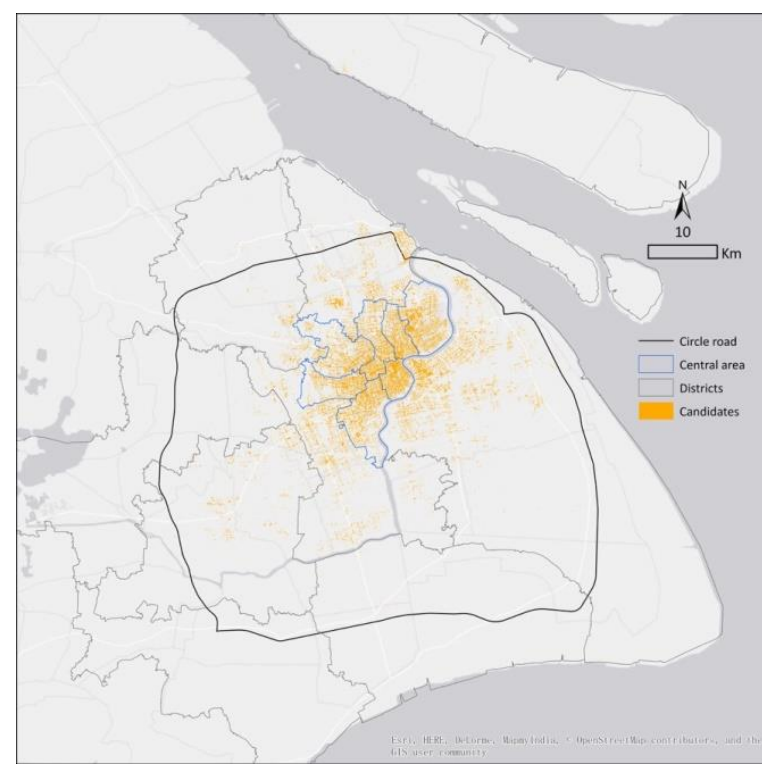

D

Figure 2. Study area (A), road network (B), parking demand (C), and location candidates (D).

\section{Step 1: Construct road network}

We constructed bikeable road network in Shanghai (Figure 2B). The total length of roads is 
26,900 kilometres. This road network includes 116.9 thousand street segments and 80.9 thousand street nodes.

\section{Step 2: Extract parking demand from bike trips}

The data used here are formally authorised by a service provider Mobike. This dataset, covering 15-30 September 2017, contains bike trips generated by users registered in Shanghai. After selecting the trips for which the ODs are both in Shanghai, we obtained 777,896 trips with 298,998 bikes. Bike parking demand can be extracted directly from the users' ODs. We divide Shanghai into uniform cells with a width of 50 metres and a length of 50 metres and then count the number of ODs in each cell. Among all 2,718,296 urban cells in Shanghai, 186,881 cells have been used as a parking space at least once. As shown in Figure 2C, most of the parking demand is inside the main circle road.

\section{Step 3: Select location candidates for electric fences}

We select all urban cells with a parking demand larger than 5 ODs as location candidates for electric fences. There are 58,941 urban cells in total. Figure 2D shows most of the location candidates are inside the main circle road and especially concentrated in the central area.

\section{Step 4: Select locations for electric fences}

We solve the location-allocation model by using the maximise coverage method. The impedance cut-off considered for the network distance was 200 metres (i.e., $D=200$ ), which was deemed to be a suitable distance for pedestrian access to bikes (García-Palomares et al., 2012). By adopting this cut-off, we assume that an electric fence can cover the demand within a network distance of 200 metres. The number of planned electric fences $(p)$ are determined via referring to two electric fence projects, which are currently being tested in China. One project in Beijing has 20 electric fences with a capacity of 2000 bikes (i.e., 100 bikes per electric fence in average) (Beijing Evening News, 2017), whereas another project in 
Hangzhou has 38 electric fences with a capacity of 1000 bikes (i.e., 26.3 bikes per electric fence in average) (Hangzhou Daily, 2017). Referring to these capacities, we need 2,990 and 11,369 electric fences to ensure that all 298,998 bikes could be docked at one of the planned electric fences (i.e., $p_{\min }=2,990$ and $p_{\max }=11,369$ ).

We consider six scenarios to illustrate our results of the location-allocation model, based on the total number of planned electric fences: 2,500 (A); 5,000 (B); 7,500 (C); 10,000 (D); $12,500(\mathrm{E})$; and 15,000 (F) (shown in Figure 3). When the number of planned electric fences is 2,500, most are located in the central area and part of Pudong New District, which is adjacent to the central area. As the number of planned electric fences increases, electric fences expand quickly from the central area to the suburban area, although most of them are still in the main circle road.

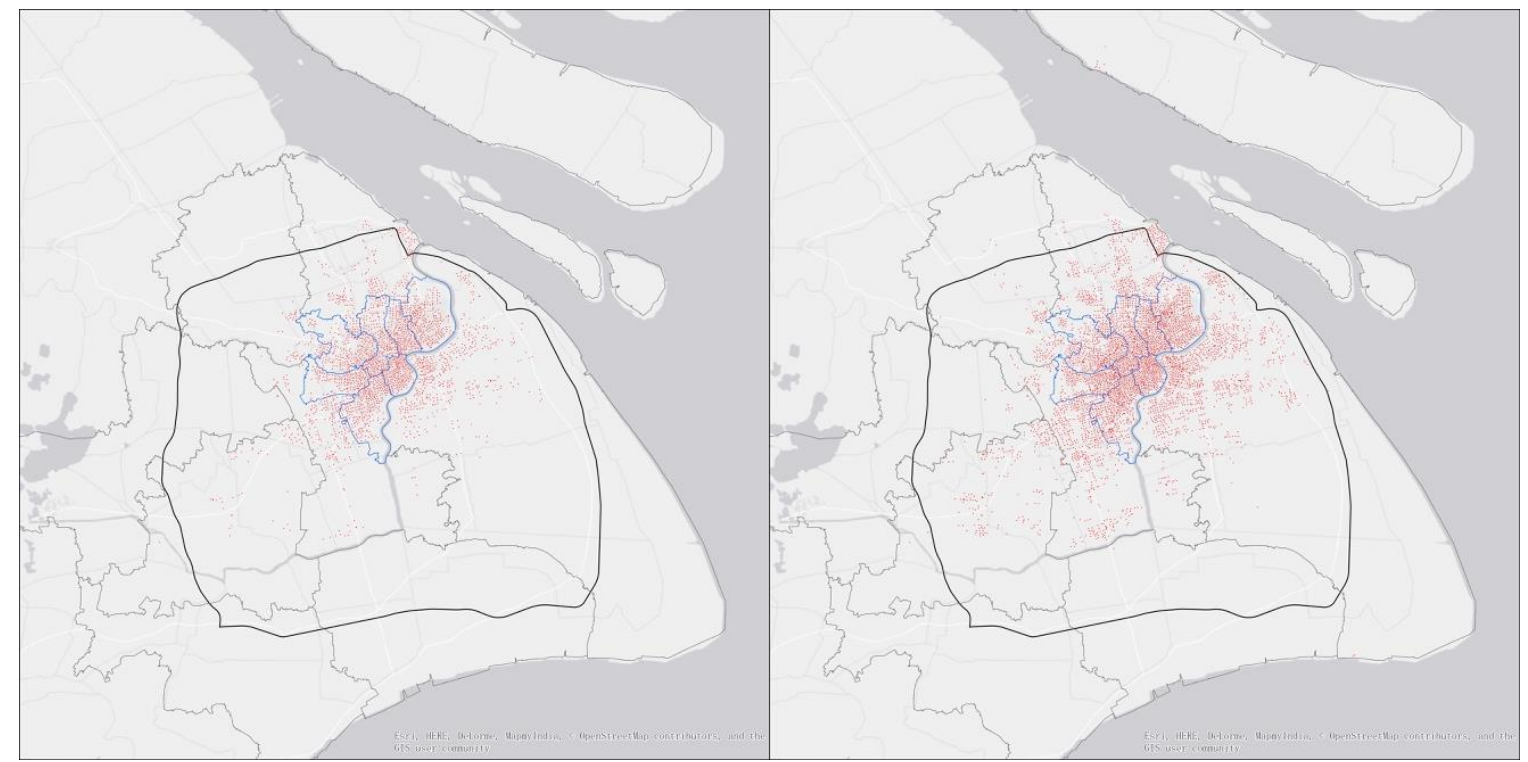

A 


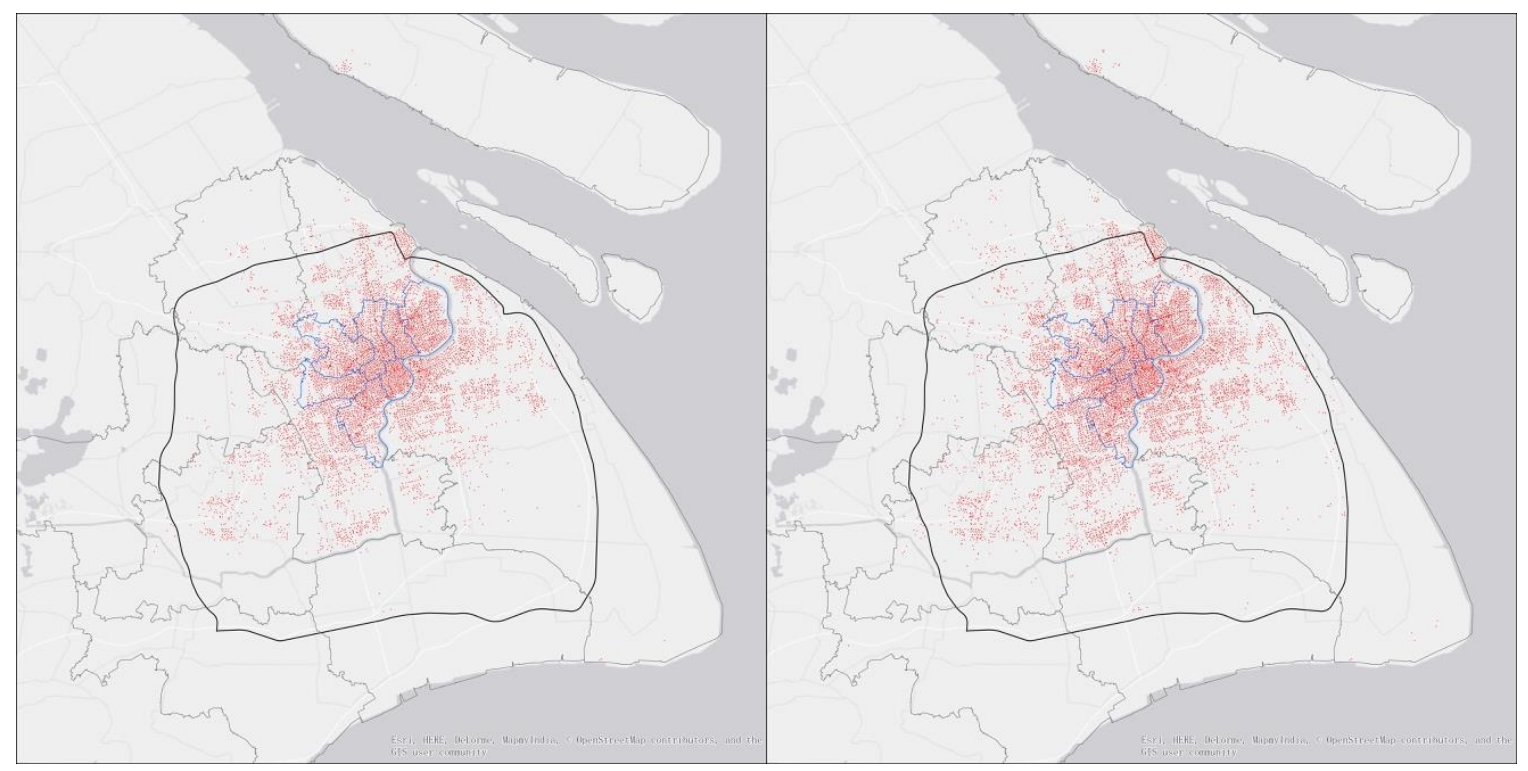

C

D

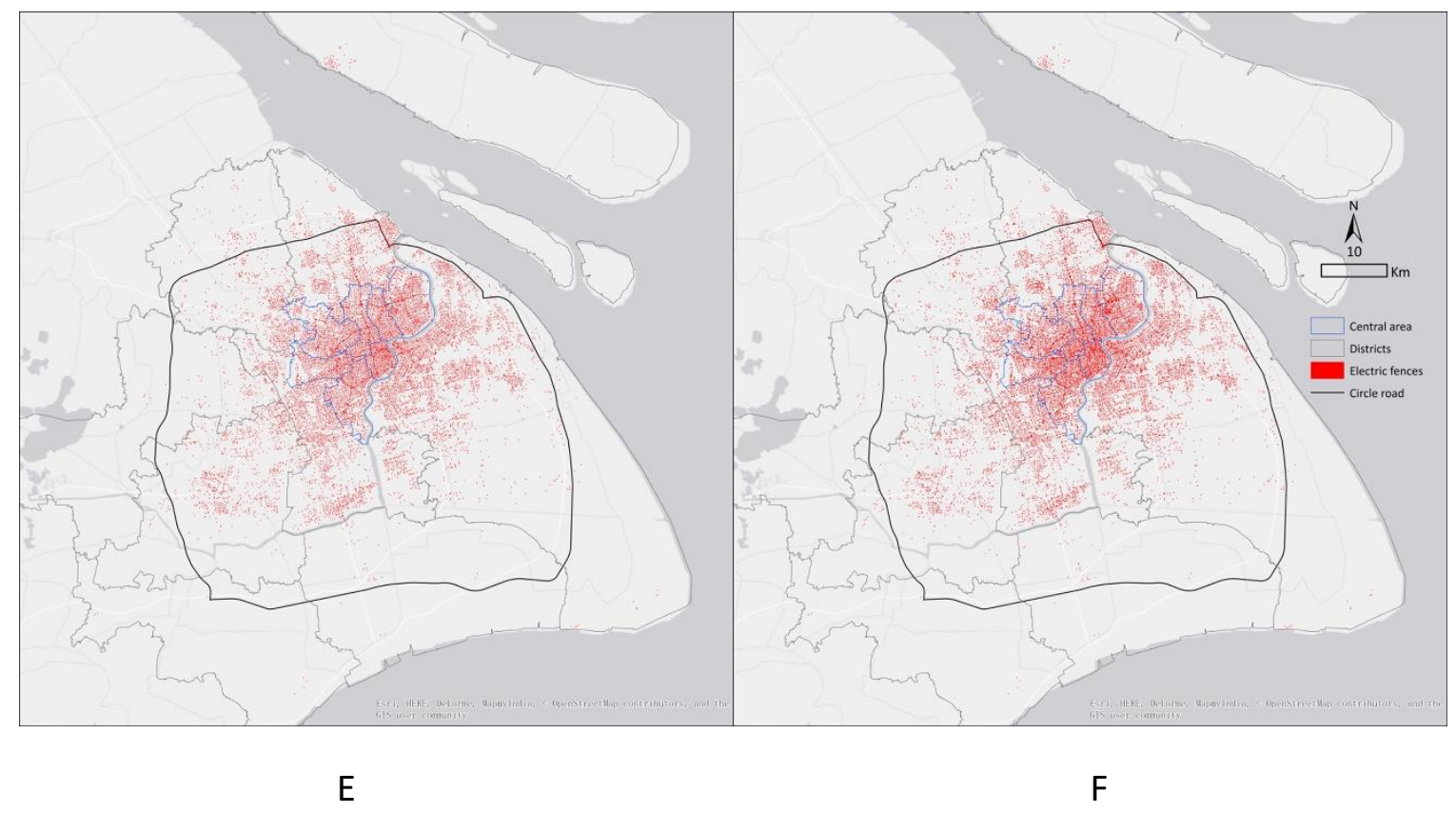

Figure 3. Results from the location-allocation model.

Table 1 shows diminishing returns with an increase in the number of planned electric fences. When the number of electric fences is $2,500,68.2 \%$ of parking demand is covered. An increase of 2,500 electric fences from Scenario A to B means a marked rise in covered demand (from $68.2 \%$ to $85.0 \%$ ). However, increases in the covered demand are much lower with further increases in the number of electric fences. An increase from Scenario $B$ to $C$ 
creates a $6.8 \%$ rise in the covered demand. An increase from 7,500 to 10,000 electric fences means an increase of only $3.2 \%$ in the covered demand. Scenario $C(7,500$ electric fences $)$ is the first scenario that covers more than $90 \%$ of the parking demand; thus, this scenario is considered an optimal electric fence plan because it can ensure a high level of demand coverage with a relatively acceptable number of electric fences. We further illustrate the analysis based on this scenario. Noted that other scenarios may also be an optimal plan, depending on the requirement of relevant stakeholders. For example, they may be more interesting in a plan covering a high demand, then Scenario F will be definitely the best.

Table 1. Percentage of covered parking demand.

\begin{tabular}{|c|c|c|c|c|c|c|}
\hline \multirow{2}{*}{ Scenarios } & \multicolumn{6}{|c|}{ Number of planned electric fences } \\
\hline & 2,500 & 5,000 & 7,500 & 10,000 & 12,500 & 15,000 \\
\hline Percentages & & & & & & \\
\hline $\begin{array}{l}\text { of covered } \\
\text { demand (\%) }\end{array}$ & 68.2 & 85.0 & 91.8 & 95.0 & 96.3 & 96.4 \\
\hline
\end{tabular}

\section{Step 5: Determine capacities of electric fences}

In Scenario C, there are 7,500 planned electric fences, the average capacity of each electric fence is 40 bikes by ensuring all 298,998 bikes can be docked at an electric fence. To determine capacities of electric fences, at first, the number of bikes to be docked in each electric fence is determined in proportion to the demand allocated to each electric fence. We then consider the following fixed capacity levels in this study: 10, 20, 50, 100, 150, and 200 or above bikes. For example, if the number of bikes to be docked at an electric fence according to the covered parking demand is 13 bikes, the capacity is then designed as 10 bikes. Table 2 shows that most electric fences can hold 20 bikes, followed by 50 and 10 bikes. At least 286,480 bikes (95.8\%) can be docked at one of the planned electric fences.

Table 2. Capacities of the planned electric fences determined in Scenario C. 


\begin{tabular}{|c|c|c|c|c|c|c|c|}
\hline & \multicolumn{6}{|c|}{ Number of bikes can be docked according to the covered } & \multirow{3}{*}{ In total } \\
\hline & \multicolumn{6}{|c|}{ demand } & \\
\hline & $0-15$ & $15-35$ & $35-75$ & $75-125$ & $125-175$ & $175-$ & \\
\hline $\begin{array}{c}\text { Fixed capacity } \\
\text { levels }\end{array}$ & 10 & 20 & 50 & 100 & 150 & $>=200$ & \\
\hline $\begin{array}{c}\text { Number of } \\
\text { electric fences }\end{array}$ & 1,956 & 2,576 & 2,024 & 654 & 184 & 106 & 7,500 \\
\hline $\begin{array}{l}\text { Number of bikes } \\
\text { can be docked }\end{array}$ & 19,560 & 515,20 & 101,200 & 65,400 & 27,600 & $>=21,200$ & $>=286,480$ \\
\hline
\end{tabular}

\section{Step 6: Recommend accurate places in selected locations}

Suitable values for two parameters in DB-SCAN must be selected when identifying the OD clusters in selected locations: Eps, the search radius of neighbourhood; and MinPts, the minimum number of demand points in an Eps neighbourhood. Both of these values should be small to avoid finding large clusters with OD outliers. We set Eps as 3 metres and MinPts as 2 ODs, and these values can represent a suitable value combination in the context of our study.

Among the 7,500 selected locations, 6,770 locations (90.3\%) have been successfully identified as having clusters with the largest number of ODs in each location. The average area of the minimum bounding rectangle of the cluster with the largest number of ODs is $25.5 \mathrm{~m}^{2}$, and the total area of all minimum bounding rectangles is 172.4 thousand $\mathrm{m}^{2}$. Because the average area is small, visualising the results for the entire city is difficult. Instead, we present our results in several typical urban contexts (Figure 4). As the results show, our method can help us efficiently and accurately determine suitable sites in selected locations for establishing electric fences. For example, Figure $4 \mathrm{C}$ shows an accurate site in a selected location near a bus stop and a hospital, while Figure 4G shows an accurate site in a selected location (left one) in front of a university canteen and an accurate site in a selected location (right one) in front of a university library. 


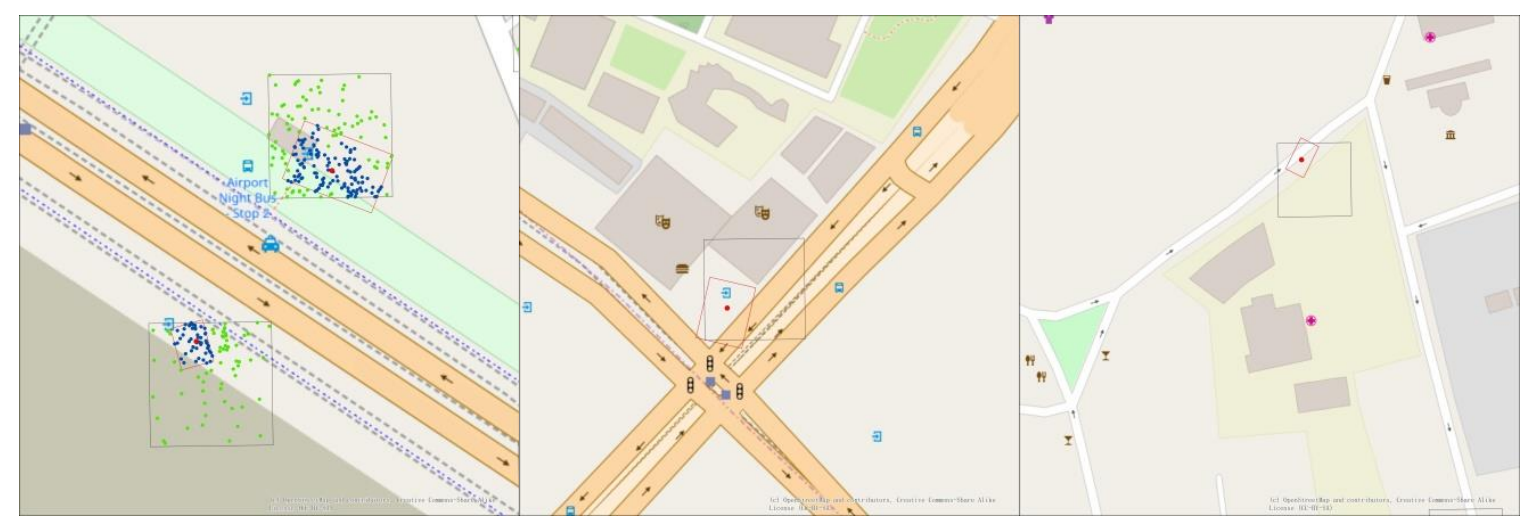

A

B

C

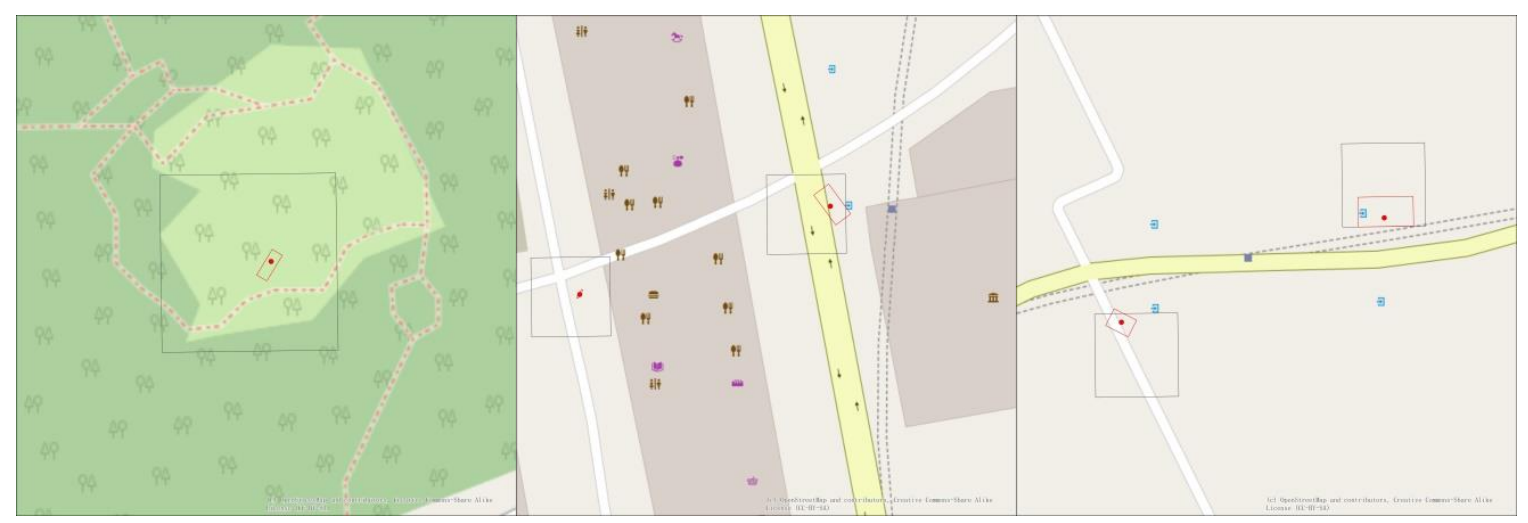

D

$E$

$\mathrm{F}$

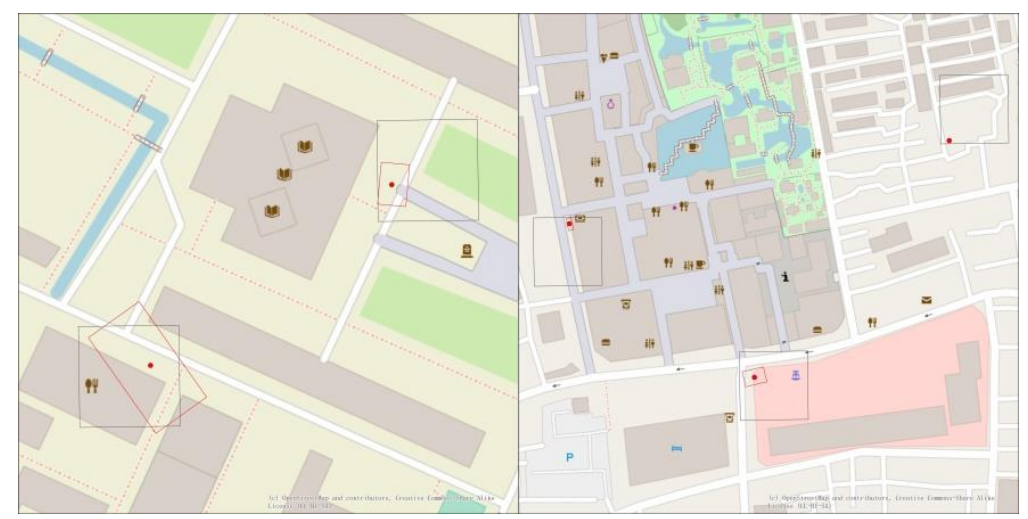

- ODs

- The OD clusters with the largest number of ODs

- Mean centres of the largest clusters

Minimum bounding rectangles of the largest clusters Selected locations for electric fences

G

$\mathrm{H}$

Figure 4. Examples of recommended accurate sites in selected locations for electric fences.

\section{Conclusions and discussion}

A new generation of bike-sharing services is emerging in China. By using this service, bikes can be unlocked and paid by using a smartphone and then picked up and left anywhere at 
users' convenience. The unprecedented development of dockless bike-sharing services results in considerable socioeconomic and environmental benefits but also creates new urban issues. One of the most severe issues is inappropriate parking behaviour. To solve this problem, electric fence (geo-fence) policy and technology are introduced to guide users to park bikes in suggested areas. In this paper, we proposed a methodological framework to support electric fence planning for dockless bike-sharing services. We then applied our framework in a case study of Shanghai using a big dataset of bike trips. We use the maximise coverage method to solve the location-allocation model and present the results in six scenarios. Finally, we use some methods (i.e., DB-SCAN, minimum bounding rectangle, and the mean centre) to efficiently find out the accurate sites that can be recommended for setting up electric fences. It should be noted that, the final electric fence plan should be established in conjunction with other social (e.g., the willingness of local citizens), economic (e.g., the cost of electric fences and maintenance of electric fences), and institutional (e.g., the planning rules) considerations.

Besides the location plans of electric fences, we still need some technical and policy supports for the implementation of the electric fence plan. The system of electric fences works using GPS or Bluetooth signals to determine the proximity between bikes and designated zones. Bike riders will be guided through their app or navigation voices to proper parking locations. In addition, service providers can introduce various incentives or punitive policies, for example, users who park bikes outside the electric fences cannot lock them and will continue to be charged, or users who park bikes properly inside the electric fences will be given some cash bonus. By these supplementary supports, the electric fence plan can well regulate the users' inappropriate parking behaviour.

There are some implications for this study. First, to better manage the users' parking behaviour, electric fences is preferred to be used for all types of bikes provided by different companies to reduce the management burden on bike service providers, and parking 
information should be provided in real time so that operators can manage the bikes among different electric fences instantly and users can identify locations with sufficient parking space. Second, we should plan a sufficient number of electric fences at suitable locations. A limited number of electric fences will mitigate the advantage of 'docklessness', and make users inconvenient to find and park bikes. According to our case study, in Shanghai, a plan with 7,500 electric fences is considered an optimal one because it can ensure a high level of demand coverage (91.8\%) with a relatively acceptable number of electric fences. In addition, the plan can ensure that at least $95.8 \%$ of all bikes can be docked at one of the planned electric fences. Third, there exists an obvious uneven distribution of electric fences and parking demand between the Shanghai central area and its suburban area, implying citizens live in the suburban area have a low level of accessibility to the dockless bike-sharing services. In order to avoid the potential issue of social inequality, it is worthwhile to explore the possibility to set up more electric fences in the suburban area.

This study can be improved and extended in several ways. First, we only discussed plans for electric fences used to guide users to park bikes in designated zones, and our discussion can be extended to plans for electric fences implemented to prevent users from parking bikes in prohibited regions via a combination of various constraining urban plans in cities. Second, in addition to considering parking demand, we can also quantitatively incorporate other social, economic, and institutional factors into the process of electric fence planning, such as the factor 'the cost of electric fences'. Third, we have discussed our study with several Mobike's senior scientists in March 2018. They appreciated our methods and analysis, and presented some interest to adopt our solution to regulate users' behaviour. In the future, we may explore the possibility to apply our methods to support the electric fence planning by cooperating with Mobike's research team. And finally, based on our framework, we can support electric fence planning for other service providers (e.g., ofo), assuming bike trip data are available. Using trip data provided by several main service providers, we may further make a comprehensive electric fence plan, which can ensure the established electric fences 
are public and free for all the dockless sharing bikes.

\section{Acknowledgements}

This research is funded by a scholarship from the China Scholarship Council (CSC NO. 201508060122). The authors would like to thank the data support from Mobike company. The authors would like to thank the anonymous referees for the valuable comments that greatly improved this article.

\section{Appendix}

1. OpenStreetMap (OSM) is a free, editable map of the whole world that is being built by volunteers and released with an open-content license, and has become one of the most popular ways to obtain free geographic data. For further information, please refer to https://www.openstreetmap.org.

2. OSMnx is a tool for downloading administrative boundary shapes and street networks from OpenStreetMap. By setting parameters in OSMnx, we can easily extract bikeable roads in Shanghai for our research purpose. Boeing (2017) has provided a detailed explanation about this package, and the readers can also find detailed information via https://github.com/gboeing/osmnx.

3. ArcGIS is the most successful commercial GIS (Geographic Information System) software in the world. It provides numerous tools for mapping and spatial analysis. For further information, please refer to https://www.esri.com/en-us/arcgis.

4. DB-SCAN (density-based spatial clustering of applications with noise) is one of the most common clustering algorithms and also most cited in scientific literature. For further information, please refer to the existing studies (Ester et al., 1996; Zhang and Liu, 2018).

\section{References}


Ai, Y., Li, Z., Gan, M., Zhang, Y., Yu, D., Chen, W., Ju, Y., 2018. A deep learning approach on short-term spatiotemporal distribution forecasting of dockless bike-sharing system. Neural Comput. Appl. 1-13. doi:10.1007/s00521-018-3470-9

Bachand-Marleau, J., Lee, B., El-Geneidy, A., 2012. Better Understanding of Factors Influencing Likelihood of Using Shared Bicycle Systems and Frequency of Use. Transp. Res. Rec. J. Transp. Res. Board 2314, 66-71. doi:10.3141/2314-09

Bao, J., He, T., Ruan, S., Li, Y., Zheng, Y., 2017. Planning Bike Lanes based on Sharing-Bikes' Trajectories, in: Proceedings of the 23rd ACM SIGKDD International Conference on Knowledge Discovery and Data Mining - KDD '17. ACM Press, New York, New York, USA, pp. 1377-1386. doi:10.1145/3097983.3098056

Beecham, R., Wood, J., Bowerman, A., 2014. Studying commuting behaviours using collaborative visual analytics. Comput. Environ. Urban Syst. 47, 5-15. doi:10.1016/j.compenvurbsys.2013.10.007

Beijing Evening News, 2017. Beijing is setting up electric fences in Chaoyang District. Beijing Evening News.

Boeing, G., 2017. OSMnx: New methods for acquiring, constructing, analyzing, and visualizing complex street networks. Comput. Environ. Urban Syst. 65, 126-139. doi:10.1016/J.COMPENVURBSYS.2017.05.004

Buck, D., Buehler, R., Happ, P., Rawls, B., Chung, P., Borecki, N., 2013. Are Bikeshare Users Different from Regular Cyclists? Transp. Res. Rec. J. Transp. Res. Board 2387, 112-119. doi:10.3141/2387-13

Buehler, R., 2012. Determinants of bicycle commuting in the Washington, DC region: The role of bicycle parking, cyclist showers, and free car parking at work. Transp. Res. Part D Transp. Environ. 17, 525-531. doi:10.1016/j.trd.2012.06.003

Campbell, A.T., Eisenman, S.B., Lane, N.D., Miluzzo, E., Peterson, R.A., Lu, H., Zheng, X., Musolesi, M., Fodor, K., Ahn, G.-S., 2008. The Rise of People-Centric Sensing. IEEE Internet Comput. 12, 12-21. doi:10.1109/MIC.2008.90

Caulfield, B., O'Mahony, M., Brazil, W., Weldon, P., 2017. Examining usage patterns of a 
bike-sharing scheme in a medium sized city. Transp. Res. Part A Policy Pract. 100, 152161. doi:10.1016/j.tra.2017.04.023

Chang, S., Song, R., He, S., Qiu, G., 2018. Innovative Bike-Sharing in China: Solving Faulty Bike-Sharing Recycling Problem. J. Adv. Transp. 2018, 1-10. doi:10.1155/2018/4941029

Chen, M., Wang, D., Sun, Y., Liu, C., Bai, Z., 2017. Service Evaluation of Public Bicycle Scheme from a User Perspective. Transp. Res. Rec. J. Transp. Res. Board 2634, 28-34. doi:10.3141/2634-04

Chen, M., Wang, D., Sun, Y., Waygood, E.O.D., Yang, W., 2018. A comparison of users' characteristics between station-based bikesharing system and free-floating bikesharing system: case study in Hangzhou, China. Transportation (Amst). 1-16. doi:10.1007/s11116-018-9910-7

Cooper, L., 1963. Location-Allocation Problems. Oper. Res. 11, 331-343. doi:10.1287/opre.11.3.331

El-Assi, W., Salah Mahmoud, M., Nurul Habib, K., 2017. Effects of built environment and weather on bike sharing demand: a station level analysis of commercial bike sharing in Toronto. Transportation (Amst). 44, 589-613. doi:10.1007/s11116-015-9669-z

Erdoğan, G., Battarra, M., Wolfler Calvo, R., 2015. An exact algorithm for the static rebalancing problem arising in bicycle sharing systems. Eur. J. Oper. Res. 245, 667-679. doi:10.1016/j.ejor.2015.03.043

Ester, M., Kriegel, H.-P., Sander, J., Xu, X., 1996. A density-based algorithm for discovering clusters in large spatial databases with noise., in: Kdd. pp. 226-231.

Faghih-Imani, A., Eluru, N., El-Geneidy, A.M., Rabbat, M., Haq, U., 2014. How land-use and urban form impact bicycle flows: Evidence from the bicycle-sharing system (BIXI) in Montreal. J. Transp. Geogr. 41, 306-314. doi:10.1016/j.jtrangeo.2014.01.013

Forma, I.A., Raviv, T., Tzur, M., 2015. A 3-step math heuristic for the static repositioning problem in bike-sharing systems. Transp. Res. Part B Methodol. 71, 230-247. doi:10.1016/j.trb.2014.10.003

Frade, I., Ribeiro, A., 2015. Bike-sharing stations: A maximal covering location approach. 
Transp. Res. Part A Policy Pract. 82, 216-227. doi:10.1016/J.TRA.2015.09.014

Fuller, D., Gauvin, L., Kestens, Y., Daniel, M., Fournier, M., Morency, P., Drouin, L., 2011. Use of a new public bicycle share program in Montreal, Canada. Am. J. Prev. Med. 41, 80-83. doi:10.1016/j.amepre.2011.03.002

García-Palomares, J.C., Gutiérrez, J., Latorre, M., 2012. Optimizing the location of stations in bike-sharing programs: A GIS approach. Appl. Geogr. 35, 235-246. doi:10.1016/J.APGEOG.2012.07.002

Habib, K.N., Mann, J., Mahmoud, M., Weiss, A., 2014. Synopsis of bicycle demand in the City of Toronto: Investigating the effects of perception, consciousness and comfortability on the purpose of biking and bike ownership. Transp. Res. Part A Policy Pract. 70, 67-80. doi:10.1016/j.tra.2014.09.012

Hangzhou Daily, 2017. The use of electric fences in Hanghzou. Hangzhou Dly.

Harkey, D., Reinfurt, D., Knuiman, M., 1998. Development of the Bicycle Compatibility Index. Transp. Res. Rec. J. Transp. Res. Board 1636, 13-20. doi:10.3141/1636-03

Ji, S., Cherry, C.R., Han, L.D., Jordan, D.A., 2014. Electric bike sharing: simulation of user demand and system availability. J. Clean. Prod. 85, 250-257. doi:10.1016/J.JCLEPRO.2013.09.024

Kabak, M., Erbaş, M., Çetinkaya, C., Özceylan, E., 2018. A GIS-based MCDM Approach for the Evaluation of Bike-share Stations. J. Clean. Prod. doi:10.1016/J.JCLEPRO.2018.08.033

Landis, B., Vattikuti, V., Brannick, M., 1997. Real-Time Human Perceptions: Toward a Bicycle Level of Service. Transp. Res. Rec. J. Transp. Res. Board 1578, 119-126. doi:10.3141/1578-15

List, G., Mirchandani, P., 1991. An Integrated Network/Planar Multiobjective Model for Routing and Siting for Hazardous Materials and Wastes. Transp. Sci. 25, 146-156. doi:10.1287/trsc.25.2.146

Liu, N., Huang, B., Chandramouli, M., 2006. Optimal Siting of Fire Stations Using GIS and ANT Algorithm. J. Comput. Civ. Eng. 20, 361-369. doi:10.1061/(ASCE)0887-3801(2006)20:5(361) 
Liu, Z., Shen, Y., Zhu, Y., 2018. Inferring Dockless Shared Bike Distribution in New Cities, in: Proceedings of the Eleventh ACM International Conference on Web Search and Data Mining - WSDM '18. ACM Press, New York, New York, USA, pp. 378-386. doi:10.1145/3159652.3159708

Ma, Y., Lan, J., Thornton, T., Mangalagiu, D., Zhu, D., 2018. Challenges of collaborative governance in the sharing economy: The case of free-floating bike sharing in Shanghai. J. Clean. Prod. 197, 356-365. doi:10.1016/j.jclepro.2018.06.213

Martens, K., 2007. Promoting bike-and-ride: The Dutch experience. Transp. Res. Part A Policy Pract. 41, 326-338. doi:10.1016/J.TRA.2006.09.010

O’Brien, O., Cheshire, J., Batty, M., 2014. Mining bicycle sharing data for generating insights into sustainable transport systems. J. Transp. Geogr. 34, 262-273. doi:10.1016/j.jtrangeo.2013.06.007

Ogilvie, F., Goodman, A., 2012. Inequalities in usage of a public bicycle sharing scheme: Socio-demographic predictors of uptake and usage of the London (UK) cycle hire scheme. Prev. Med. (Baltim). 55, 40-45. doi:10.1016/j.ypmed.2012.05.002

Pal, A., Zhang, Y., 2017. Free-floating bike sharing: Solving real-life large-scale static rebalancing problems. Transp. Res. Part C Emerg. Technol. 80, 92-116. doi:10.1016/j.trc.2017.03.016

Pan, L., Cai, Q., Fang, Z., Tang, P., Huang, L., 2018. Rebalancing Dockless Bike Sharing Systems.

Park, C., Sohn, S.Y., 2017. An optimization approach for the placement of bicycle-sharing stations to reduce short car trips: An application to the city of Seoul. Transp. Res. Part A Policy Pract. 105, 154-166. doi:10.1016/J.TRA.2017.08.019

Pfrommer, J., Warrington, J., Schildbach, G., Morari, M., 2014. Dynamic Vehicle Redistribution and Online Price Incentives in Shared Mobility Systems. IEEE Trans. Intell. Transp. Syst. 15, 1567-1578. doi:10.1109/TITS.2014.2303986

Rahman, S., Smith, D.K., 2000. Use of location-allocation models in health service development planning in developing nations. Eur. J. Oper. Res. 123, 437-452. doi:10.1016/S0377-2217(99)00289-1 
Reidy, M.M., Campbell, T.A., Hewitt, D.G., 2008. Evaluation of Electric Fencing to Inhibit Feral Pig Movements. J. Wildl. Manage. 72, 1012-1018. doi:10.2193/2007-158

Rixey, R.A., 2013. Station-Level Forecasting of Bikesharing Ridership. Transp. Res. Rec. J. Transp. Res. Board 2387, 46-55. doi:10.3141/2387-06

Rybarczyk, G., Wu, C., 2010. Bicycle facility planning using GIS and multi-criteria decision analysis. Appl. Geogr. 30, 282-293. doi:10.1016/J.APGEOG.2009.08.005

Shaheen, S., Zhang, H., Martin, E., Guzman, S., 2011. China's Hangzhou Public Bicycle. Transp. Res. Rec. J. Transp. Res. Board 2247, 33-41. doi:10.3141/2247-05

Shen, Y., Zhang, X., Zhao, J., 2018. Understanding the usage of dockless bike sharing in Singapore. Int. J. Sustain. Transp. 1-15. doi:10.1080/15568318.2018.1429696

Shi, J., Si, H., Wu, G., Su, Y., Lan, J., 2018. Critical Factors to Achieve Dockless Bike-Sharing Sustainability in China: A Stakeholder-Oriented Network Perspective. Sustainability 10, 2090. doi:10.3390/su10062090

Spinney, J., Lin, W.-I., 2018. Are you being shared? Mobility, data and social relations in Shanghai's Public Bike Sharing 2.0 sector. Appl. Mobilities 3, 66-83. doi:10.1080/23800127.2018.1437656

Teixeira, J., Antunes, A., Peeters, D., 2007. An Optimization-Based Study on the Redeployment of a Secondary School Network. Environ. Plan. B Plan. Des. 34, 296-315. doi:10.1068/b31173

The Centre for Sharing Economy, 2017. The Research Report on Bike-sharing Employment.

Tian, Z., Wang, J., Wang, J., Zhang, H., 2018. A multi-phase QFD-based hybrid fuzzy MCDM approach for performance evaluation: A case of smart bike-sharing programs in Changsha. J. Clean. Prod. 171, 1068-1083. doi:10.1016/J.JCLEPRO.2017.10.098

Transport for London, 2017. Dockless bike share - code of practice for operators in London. London.

van Waes, A., Farla, J., Frenken, K., de Jong, J.P.J., Raven, R., 2018. Business model innovation and socio-technical transitions. A new prospective framework with an application to bike sharing. J. Clean. Prod. 195, 1300-1312. doi:10.1016/J.JCLEPRO.2018.05.223 
Verter, V., Lapierre, S.D., 2002. Location of Preventive Health Care Facilities. Ann. Oper. Res. 110, 123-132. doi:10.1023/A:1020767501233

Wood, J., Slingsby, A., Dykes, J., 2011. Visualizing the dynamics of London's bicycle hire scheme. Cartogr. Int. J. Geogr. Inf. Geovisualization 46, 239-251. doi:10.3138/carto.46.4.239

Xin, F., Chen, Y., Wang, X., Chen, X., 2018. Cyclist Satisfaction Evaluation Model for Free-Floating Bike-Sharing System: A Case Study of Shanghai. Transp. Res. Rec. J. Transp. Res. Board. doi:10.1177/0361198118770193

Yu, D., Shang, L., 2018. Opportunities and Challenges Faced by Share Economy: Taking Sharing Bicycle as an Example. DEStech Trans. Econ. Bus. Manag. 0. doi:10.12783/dtem/icmed2017/19328

Zaltz Austwick, M., O’Brien, O., Strano, E., Viana, M., 2013. The Structure of Spatial Networks and Communities in Bicycle Sharing Systems. PLoS One 8, e74685. doi:10.1371/journal.pone.0074685

Zhang, L., Zhang, J., Duan, Z.Y., Bryde, D., 2015. Sustainable bike-sharing systems: Characteristics and commonalities across cases in urban China. J. Clean. Prod. 97, 124133. doi:10.1016/j.jclepro.2014.04.006

Zhang, Y., Liu, L., 2018. Understanding temporal pattern of human activities using Temporal Areas of Interest. Appl. Geogr. 94, 95-106. doi:10.1016/J.APGEOG.2018.03.009

Zhang, Y., Mi, Z., 2018. Environmental benefits of bike sharing: A big data-based analysis. Appl. Energy 220, 296-301. doi:10.1016/j.apenergy.2018.03.101

Zhang, Y., Thomas, T., Brussel, M., van Maarseveen, M., 2017. Exploring the impact of built environment factors on the use of public bikes at bike stations: Case study in Zhongshan, China. J. Transp. Geogr. 58, 59-70. doi:10.1016/j.jtrangeo.2016.11.014

Zhou, S., Ni, Y., 2018. Effects of Dockless Bike on Modal Shift in Metro Commuting: A Pilot Study in Shanghai. 